\title{
TURNING FROM THE MARGINS: DISCOURSING HEIDEGGER AT THE END OF LIFE AS WE KNOW IT ${ }^{1}$
}

\author{
Agustin Martin G. Rodriguez \\ Ateneo de Manila University \\ arodriguez@ateneo.edu
}

\begin{abstract}
The essay discusses Heidegger's almost mystical understanding of the Turning after the era of the forgetfulness of Being and his warning of the danger of Western technology. Critically exploring Heidegger's conception of this danger, the essay proposes that the danger of Western technology can be creatively engaged by the rationalities that were marginalized by its propagation. The essay shows that the "less developed" nations still comprehend the world according to the rationalities marginalized by the Westernization of the world, and these rationalities bear with them the possibility of bringing the dominant world rationality to a more rational and creative way of being in the world. It posits that the turning that Heidegger envisions will emerge from the discourse between dominant rationalities caught in their forgetfulness of Being and the marginalized rationalities that bear a level of naivete from traditional ways of being in the world. From this discourse will emerge a second naivete which will bring about a more creative being in the world.
\end{abstract}

\section{Keywords}

discourse theory, rationality, sustainable development, marginalization, global justice, environmental degradation

\begin{abstract}
About the Author
Agustin Martin G. Rodriguez is a professor of philosophy at the Ateneo de Manila University. He has published on poverty and sustainable development using the lens of discourse theory. He has also written on Scheler, Derrida, Heidegger, and Habermas and is currently the President of the Asian Association of Christian Philosophers.
\end{abstract}


OURS IS A TIME OF DANGER. It is a time when the very existence of our species is threatened, and, without a doubt, life as we know it is surely coming to an end. What greater danger is there than the end of the systems of production that have supported the trappings of wellbeing of a considerable percentage of our population? That danger will manifest itself in the next few decades as oil production peaks and every petroleum dependent system collapses (Howden). Some analysts claim that oil can be replaced by renewable resources of energy (Sachs 43). However, even our fertilizers are petroleum-based and it will take a massive overhaul of our farming systems, as well as our food processing systems, for us to cope with its loss (Roberts 223). But no government is seriously undertaking this overhaul. By all indications, the end of cheap and abundant oil will bring much suffering before our systems can even begin to turn around.

What greater danger is there than the end of free and abundant water? And we do face that era in the near future. There will come a time when our children and their children will fight wars over potable water supplies and the right to access irrigation (Interlandi). Because of deforestation, especially the loss of rainforests; global warming, which changes rainfall patterns and makes more regular the occurrence of drought; and the pollution of clean water sources, water will be scarce and difficult to access (Gore 99-100). Thirst and hunger may define our state in the coming times.

What greater danger is there than the warming of the climate which will bring about extreme weather patterns? Yet extreme floods, extreme droughts, harsher typhoons, and the transformation of habitats to inhospitable environments will afflict many of the earth's inhabitants within this century. The death of species, which we are already destroying at the level of thousands a year, will be exacerbated in the coming times (Wilson et al.). We do not know if human beings will fare better than our fellow dwellers in this world when the dangers become manifest.

We face a time of threat and tragedy, and our very existence and the continuance of the present forms of life on earth is at risk. The root of all this danger lies-as Heidegger has pointed out so many decades ago-in the way we were ordained to be in the world. In his works on dwelling and technology, he points out that we were ordained by Being to dwell in this world in a kind of forgetfulness of Being. In a way, we were determined to be in the world in a way that reduces all that comes to presence to standing reserve ("Question" 23). For him, we have been made to engage the world in a manner that is reductive. Things are no longer allowed to stand forth from Being. They are not allowed to stand forth at all as things but only allowed to be present as objects ("The Thing" 181). And when we face the object, we do not experience the coming forth of what stands before us as ordained or given to presencing by Being. This essay is an exploration of Heidegger's understanding of the danger of what he calls "the essence of modern technology" as forgetting. It will discuss this Heideggerian conception of the danger of technology and show how he believed that this danger would come to a turning because the danger 
itself offers a philosophical ground for hope. Although the Heideggerian language of the ordaining of this danger is strange to the contemporary reader, it is worth exploring because, applied to the situatedness of the marginalized rationalities of non-Western cultures, we can show how the other of the West bears a responsibility to the flourishing of humanity. Thus, the essay is an exposition of how Heidegger's seemingly essentializing discourse on Western technology can show that the emergence of the dangers of modern technology are necessary and fruitful to human flourishing if the traditional rationalities of the marginalized can be empowered to discourse with the dominant rationalities of the West. Thus, the essay is not an indictment of Western rationalities. Rather, it aims to show how the danger brings a promise of greater flourishing if its other is awakened.

\section{Thinking and Enframing}

Heidegger's main insight into our contemporary way of opening to Being is that it does not allow us to let the thing stand forth. Our reductive ways shape our opening to things such that all things are reduced to object or that which is defined by human interest and calculation. He sees this as the reduction of things to standing reserve ("Question" 17). What stands forth before us is only that which stands as defined by us. Thus, no things stand before us-only objects of knowing and manipulation (21). More precisely for Heidegger, no thing stands in its ordained sending forth before human beings. All things are but mere objects to be classified, defined, and, ultimately, manipulated for human consumption. And so we have forgotten to open to the thing and to Being that ordains the things being brought forth ("Memorial Address" 50-51).

Heidegger shows in many of his late writings that this Enframing is the essence of modern technology. The essence of modern technology shapes our engagement with beings as if the human ego and its interests are the defining centers of every being's presencing. It is the letting be of beings as determined by human need and desire ("Question" 15). It gives structure to the totalizing tendencies of human beings and limits our openness to Being and beings.

Is this Enframing unique to modern and contemporary technology? It is possible that human opening to Being has always had this orientation toward reductive thinking. Certainly, we who are shaped by Western thinking have a tendency to understand beings according to how they serve us. Even the human who comes from more traditional ways of engagement has an inherent opening to the world from his interests. Because our capacity to manipulate beings was limited in more traditional rationalities, and we did not discover the capacity to see the cosmos as a machine to be understood according to mathematical relations, we had a limited effect on the coming to presence of the world. Our tendencies to reduce beings to standing reserve were always limited by a sense that beings somehow fell into an order that transcended the human artisan-that we were only a part of a greater 
whole, which we did not define and could not manipulate. That intuition kept our reductiveness in check. However, with the advent of modern science which allowed us to purge ourselves of that intuition, we began to think of nature as a machine that could be systematically understood and manipulated. At that point, our reductiveness was given license and power.

Perhaps this coming to awareness of the power of human reductiveness became possible with the Kantian epistemological postulate that our most legitimate understanding of the world is our understanding of nature as constructed by the workings of reason (Kant, "The Second Part of the Transcendental Problem"). It no longer mattered that what was given was given as thing but only that the object we constructed reasonably explained the data we received. We no longer have to inquire into the truth of our rational understanding of the world; we only have to be careful that our interpretation of nature takes into account all of the legitimate data of our senses.

With this, the human knower was given license to enframe-appropriating Heidegger's description of the essence of modern technology-without the limits of the need to speak the truth or the need to consider how a thing is made to stand forth from being. Without this limit, things only mean as we let them mean and things exist as we let them be. Since we cannot know the noumena, or what comes to presence as thing, but only as phenomena, or object of understanding, we need only to ensure that our frames are comprehensive and effective. Unshackled, we fashioned a new world according to how we understood it and could manipulate it. And what stood before us as world was no longer the world of things standing forth, but the world of comprehended objects and the realm of resources standing in reserve for our use ("Question" 16).

We no longer have a world that is brought forth from Being. What we have is a world made to stand present as human reserve by the reductive reason of man. In this reductive thinking, we powerfully built what we understood as a home, but without a living relationship with what stands forth from Being (23). We created a way of being in the world that destroyed our potential for dwelling in the world. Dominant human beings have reduced most of our engagement to beings to reductive calculation such that we have miscalculated how far the reduction to standing reserve could go, and now we have simply fouled our nest. We have created systems of producing, consuming, and thinking that eat up or simply destroy our fellow earthlings, that impoverish our fellow humans, and that denude and devastate the habitats of our embodied selves.

The evidence for this destruction is astonishingly evident. The promises of unbridled consumption implied by industrialization and the free market, and the cultural, economic, and political systems built on these promises, have caused most of humanity great suffering. The gap between the rich and the poor is widening. The number of the destitute is increasing and will continue to increase in the coming decades as the effects of global warming become more established (Dodds 6-8). 
Our dwelling has become inhospitable to our fellow earthlings and is becoming inhospitable to human life. This seems to be all our doing. This is how we have framed the world with our reductiveness. Although the heart of the destruction may be rooted in human greed, the scale of our destructiveness was made possible by our capacity to reduce the other. With the danger of Enframing, we have allowed for a great destructiveness to overcome our human becoming.

However, if Heidegger is to be believed, the rising of this danger was not mainly our human doing but was ordained by Being ("The Turning" 43). The fall to forgetfulness was determined by Being as necessary. It seems that this fall is meant not to bring humanity to an ultimate forgetfulness of Being, but is meant to bring humanity to a fuller opening to Being and what it brings forth. Enframing is a challenging, the ordained the fall for a fuller rebirth. Thus, the whole forgetfulness of Being by human dwellers was necessary for us to find a more authentic dwelling in Being with beings. Only in embracing the ordained aspect of our forgetfulness can we come to the salvation that it promises ("Question" 33).

\section{The Danger and Modern Technology}

But how does one embrace forgetfulness without falling completely into a forgetfulness that is destructive? How can we humbly accept the ordaining by Being of our forgetfulness in a way that is creative and oriented toward the turning? We must be able to engage the forgetfulness with mindfulness. What this means is to engage the way of modern technology and all other systems of Enframing, and accept what it brings-even if this includes the reductiveness-but all the while remaining mindful of the danger of its gifts ("Question" 33).

This is a difficult task because the Enframing mode of opening to being is potentially destructive and reductive, and its systems can be forceful and capable of consuming those who fall under its sway. And thus, the ways of forgetfulness could lead exactly to a complete oblivion to that which stands forth and that from which the thing stands forth. As we can see in our time, we are caught in our ordained reductiveness and we forget that what stands framed by our interest is not only what is according to our reduction but, more than that, it is that which stands forth from its givenness by Being. However, this ordained reductiveness is not to be understood in despair for it can promise a greater wholeness for the collective human becoming.

Certainly, this Enframing way of being which is made manifest in a Western, technological mode has brought forth the possibility of improving the quality of life, of extending knowledge and discovery, of reshaping the world so that it is more hospitable to human dwelling, and of curbing unnecessary suffering and death. On the other hand, this technological way of being has also brought about a destructive way of being in the world. It has made possible massive consumption that has destroyed the habitat of all earthlings, including the humans who initiated the 
danger. It has allowed the establishing of ways of life that encourage meaningless consumption and massive destructiveness. While extending life and improving its quality, it has also made it difficult for people to realize their wholeness. Thus, embracing the gift of the technological way of being in the world means recognizing the dangers of Enframing as much as we accept its benefits so that we can allow the turning that is ordained to unfold.

At the end of life-as-we-know-it, we have come to a period of great perdition brought about by a way of being in the world that tends to be destructive in its reduction of beings to standing reserve. For Heidegger, this was made most manifest by modern technology which created the atom bomb. But it is equally manifest in our other modes of being in the world: i.e. in our systems of trade, consumption, production, and culture generation. All these embody reductiveness as a human mode of engaging reality. All these modes of being in the world have contributed to our perdition - to the spoiling of our world. For some reason, the era of Enframing was ordained to be realized by Western civilizations. Not that it is inconceivable that this destruction could be brought about by the Eastern civilizations if they were allowed to flourish, but as it is, the mode of Enframing is today embodied by Western rationalities.

As Asians and Filipinos, we cannot face this danger without some sense of irony. Ours is a nation tagged to be the third on a list of nations to be worst hit by global warming (Thakker; Alave), and the ninth on a list of nations currently suffering from its present effects. We are suffering most from global warming and yet we are not among its prime instigators nor are we one of its main beneficiaries. Our cultures did not originate this reductive way of being. Clearly, the Enframing modes of being emerged from the West and most traditional cultures are still not comfortable with this ethos of reductiveness encountered in Western technologies and economic systems. Those of us in the East who have adopted Enframing ways have adopted it because of the aggressive imposition of Western nations seeking to expand their economies. And after decades of this imposition, we still do not benefit from Enframing ways. Our economies that were already devastated by colonization face even greater devastation as the effects of global warming become more manifest. Before we could even begin to properly address the massive poverty caused by Western exploitation, we face an incalculable destruction brought about by their reductive ways. We, who are brought to perdition by the essence of modern technology, even though we are not the ordained initiators of it, may look at this unfolding of the danger with bitterness. We will be worst hit by a danger that was initiated and imposed with violence by the aggressive others. And yet, this danger which threatens us, also calls us to a special vocation. The ordained danger gives us a special role in the coming to mindfulness of humanity as it faces the end of life-as-we-know-it.

According to Heidegger, the danger is ordained by Being and brought to full flowering by Western humanity. We cannot blame them, then, for developing this 
way because of Being's ordaining. Certainly, the way of engagement that reduces Being to a standing reserve did not just originate with Western man. However, the West is the channel that developed humanity's scientific and technological thinking into a way of being that has determined that the whole of reality should become a standing reserve. And upon developing this way of being in the world into a powerful economic system supported by scientific, technological, cultural, and political systems, they successfully exported these systems to other peoples until it became the dominant rationality of our global community. Because of the force of the spread of the new global rationality of consumption and the reduction to standing reserve, many of the world's people are caught in a way of being that is not creative or fulfilling for them-especially since they have to engage the world in a mode of being that is not organic to them. The indigenous people's experience of development may be understood thus:

Development is the process whereby other peoples are dominated and their destinies are shaped according to an essentially Western way of conceiving and perceiving the world. The development discourse is a part of an imperial process whereby other peoples are appropriated and turned into objects. It is an essential part of the process whereby the 'developed' countries manage, control and even create the Third World economically, politically, sociologically and even culturally. It is a process whereby the lives of some peoples, their plans, their hopes, their imaginations are shaped by others who frequently share neither their lifestyles, nor their hopes, nor their values. (Tucker qtd. in Tauli-Corpuz 50)

This is the shared experience of the Western other to the Western imposition of Enframing and thus they resist.

Fortunately, despite the strength of the imposition of the Western Enframing, other rationalities continue to shape our opening to Being. These persisting rationalities bring with them the traditions of opening from a multiverse of cultures. Many of these traditions have been rendered inutile or useless. They have been relegated to what the dominant, global rationality has condescendingly referred to as backward, superstitious, unscientific, or ineffective. But despite this, we must remember that the very reason these rationalities find themselves inutile or backward is precisely because of their inability or refusal to fully integrate themselves into the rationalities of forgetfulness. Many rationalities of the global other resist economies of scale that insist on the reduction of the human to resource. Many other rationalities of the global other resist the reduction of nature to standing reserve. Many of these rationalities resist the reduction of dwelling space to property. This resistance has preserved ways of opening that remind us that Enframing is not the only way to engage Being. 
It seems that as Being ordained the West to forgetfulness, the others of Western civilization were ordained to remember.

\section{The Turning and The Rationality of the Other}

Despite the fact that these rationalities have been marginalized and discredited, they persist as a challenge to the totality of global systems. Thinkers who are trained in the systems of the dominant rationalities and who are immersed in the lifeworld of traditional rationalities are positioned at a point where they bridge these two rationalities and perhaps allow them to dialogue. The primary agenda of the thinkers between rationalities should be to engage the marginalized rationalities and articulate to the dominant rationalities the others' modes of opening because, as we come to face the danger of the thinking of Enframing, we need to infuse global thinking with less destructive ways of being that will allow for the ordained forgetfulness to make its turning toward a more genuine letting be of things. Global civilization has grown much from the opening to marginalized rationalities. Organic farming methodologies, alternative medicine, and intermediate technology methodologies have brought to world rationalities other ways of opening to Being such that humanity has found more sustainable and less intrusive systems of production, trade and consumption.

It has been ordained that we fall into a mode of opening that had led to the forgetfulness of Being. Being has ordained the forgetting. In ordaining the forgetting, we were made to realize a destructive way of being but not to fall into utter perdition and forgetfulness. Perhaps, the danger of forgetting was ordained in order for human beings to be led to a more profound way of opening-one that will let the presencing presence in a way that is more faithful to the letting be of Being and to the coming forth of beings. With the fall ought to come a turning to a more authentic way of opening that was impossible without the fall. The question is this, how do we come to a fuller way of opening, of letting presence, while respecting the gift of the forgetfulness? Perhaps it is incumbent upon those who can dwell between rationalities, having adapted to the aggressive dominant rationality, and yet remaining faithful to the rationalities that shaped the dwelling of their ancestors, to participate in the new turning toward Being - a re-turn to Being after the fall, an opening to Being that is like before but a more profound turning toward Being because it was gifted with the fall.

What was the gift of the fall? Perhaps it is this: with the fall, we have come to recognize our power to be reductive totalities. With the fall, we have recognized our power to genuinely be creative along with our power to genuinely be destructive. Now that we have come to the point of bringing ourselves to extinction, we must discover how Being calls us to genuine opening. This is an opening that comes not from the naïveté of never having met our demons, but one that comes from a deep awareness of our power and our ability to destroy the coming to presence of 
that which stands forth from Being. We need a new naïveté-a hopefulness from which we know we can choose to be reductive but still choose to allow things to stand forth from their being given. We need to discover a new naïveté from which we choose to open to Being as, what Marion would call, the given to (102-103). We choose to be given to instead engaging being as reductive consciousness and will because we have understood profoundly the danger of the essence of modern technology as much as we appreciate its potential.

To be given to means to be the consciousness and will that chooses to allow the coming forth of what is given to come forth. But this opening to the coming forth is an opening that is humble while aware of its reductive powers. It is a choosing to be given to while being aware that it can choose to determine the presencing. It chooses to be given to because it appreciates the danger of the reductive consciousness and will.

However, how can we choose another possibility of opening if we are completely caught in a destructive era of Enframing? Will we only realize the danger if we are overcome by it? Being is calling us to the turning. The first sign of this in the West is the whole movement of post-modernity which has been able to articulate the danger of totality, particularly through the exposing of reductive rationality. ${ }^{2}$ It seems the time is ripe for the turning, but we must respond to its coming to fruition by fashioning ourselves to receptivity.

We who are able to bridge traditional lifeworlds and Western rationalities have much to contribute to the turning for we are the people who have been imposed upon by the violence of the Enframing, but have also been adaptable enough to understand and use the ways of the Enframing. Some nations like Japan and Korea have been successful in adopting the Western technologies to their own ways of seeing and doing and have clearly been able to build societies bordering on or marrying the traditions of reducing and patient opening. However, these societies too have, on the whole, succumbed to the values of Western technologies. Development for them is defined by increased consumption and production and the creation of technologies to facilitate profit generation. China too and all the other Asian Tigers have oriented and focused their development on "catching up" with the West or besting them at their own game. China has perfected the art of reverse engineering Western technologies to reproduce these inexpensively-and in so doing feeding the capacity of humanity to consume in massive quantities. There are cultural variations to this story of development, but in all the narratives, success is determined by how well the protagonist embraces the rationality of Enframing.

Other traditional cultures are less adaptable to Western rationalities. The most strife torn nations of Africa are the clearest examples of this as their nations are thrown into chaos with their attempts to adapt themselves to Western imposed nation states and economic systems. The poverty traps of Somalia, Kenya, and Nigeria are caused by their inability to make Western governance systems that 
serve liberal, capitalist economies work for them. It may be possible that their more indigenous systems of governance may serve them better, but the totality of Western imposed systems demand that they conform to abstractive and reductive modes of economic and political governance. Many other so-called backward economies are struggling too with the Western systems that dominate the global community. The ones having the most difficulty are those that have strong traditions of their own that they find difficult to simply disregard or merge with Western rationalities. This is most true of the Eastern peoples whose cultures clash with Western ways of doing. The constant clash of traditional Islamic and Hindu groups could be rooted in their traditional knowledge being rendered inutile by modern ways. Without romanticizing the traditional ways of these systems - a difficult thing to do when so many of them have been twisted to abuse women and their minority cultureswe can see that their traditional knowledge may still have much to tell us about sustainable and rooted ways of being. These so-called backward rationalities may have preserved traditional ways of opening to Being that will allow an other way of engaging what comes to presence. Thus, these rationalities may bear with them the other of the dominant rationality that could awaken that rationality to other ways of being in the world with others.

Our Filipino civilization is one such culture that can straddle the Enframing and traditional rationalities. We have been very adaptable. We take what other cultures offer and adapt it to our ways or adapt our ways to it. Our values adapt to our conquerors but also transform, in a quiet, subversive way their own ways of engaging the world. Ileto, for instance, shows us how the Tagalogs were able to appropriate Catholic values to translate these into the language of liberation. Our other experiences of millenarian revolts are clear examples of how Filipino peoples, for instance the Boholanos (the Dagohoy Revolt) and Ilocanos (the Guardia de Honor revolt) are able to take the discourse of the dominant rationalities to articulate native conceptions of a good society ("The Turning" and "Revolution and the Restoration"). From revolts to our adaptations of small enterprises, modes of transportation, and democratic systems, we see how the Filipino people can take imposed systems from other rationalities and transform these into something possibly fruitful. However, we have not become fully successful because we have not fully adopted the mechanistic and abstracting rationalities of the West. At least, a vast majority of us have retained values that do not exactly match Western professionalism and efficiency. We are not fully abstract, mathematical, and mechanistic in our world views (Nisbett et al. 108). Some may say that this failure to adopt Western rationalities are a failure of our education system but these could stand more for the resistance of the native to the imposition of rationalities. Even when we learn to see the world with this lens, we still also understand the world according to the moral economy of the personal forces of nature.

Thus, we have formal systems that are enriched or stumped by pakiusap, or the merit system founded on greater need, relatedness, and indebtedness. We work with 
medical systems that see the body as a machine and at the same time seek healing with healers who see the body as part of a moral system engaged with spirits and natural forces. We live in cities with rural structured houses and communities built around traditional kinship systems.3 We have adopted enough to serve Western systems but not to conquer them. We understand reductive thinking but we also understand letting be.

The way the urban poor build their communities and their homes are examples of how Filipinos straddle rationalities. What "squatter" communities show us is that ultimately, we do what we have to do to comply with enforced reductive systems but, since we are not ourselves convinced that these are the best systems with which to realize ourselves, we adapt them to what we understand is a human way of dwelling. Most urban poor communities are built according to what the dominant building rationality considers substandard design parameters. For instance, building materials, space allocation, and engineering are considered unsuitable according to formal living standards. However, upon closer examination, these building systems are based on traditional, rural community relations-initially the bahay kubo system, then later city adaptations of rural dwelling systems which place the private space open to shared spaces (Lungsod Iskwater 131-132). Our homes are built in a way that suits our need for community solidarity as much as they are a response to poverty and lack of security of land tenure (Lungsod Iskwater 132). The houses look makeshift or "bahala na," but they are actually built with an other understanding of the needs of human dwelling. In Lungsod Iskwater, Alcazaren et al. make the following observations:

The mystery of informal settlement community building lies, not where architects and planners expect it-on understanding abstract concepts of physical forms and spaces-but in understanding and learning from the informal process that created them. The key, it seems, would be to discover the "timeless way of building" and to understand and apply the principles inherent in that natural process of development to the design and planning of socialized housing and lower-income communities. (41)

They continue:

What is observed in informal settlements are patterns of organic growth. The natural process of community building creates patterns, which are replicated in various permutations - a "pattern language" so to speak. The community is established and the settlement built with these patterns of building blocks melding over time to achieve coherence and stability. We see this "little by little" (a common term that is a direct translation from the Filipino pakontikonti) approach not only in the building of homes but in the creation of the larger settlement and even districts of informality. (144) 
Even public spaces are unplanned and built pakonti-konti. They are "the result of an unconscious but integrated way of house construction and public space provision" (Alcazaren, Ferrer, and Icamina, Lungsod Iskwater 14.4) and not according to painstaking calculation over minutiae. The authors bemoan how the natural process "is being disrupted by present policies of government and international funding organizations" who do not understand the necessity of the "trellis-like structure plans," because for them it could lead to disaster (144). But despite dominant rationality interventions and dehumanizing conditions, people are able to build according to their conception of genuine dwelling. In this example of informal building, we see how Filipinos who dwell in the city straddle two rationalities and balance their lives between these rationalities. This is an example of how some rationalities can negotiate with the marginalized and the dominant effectively if not fully creatively. With this positioning between rationalities, we can act as the other voice, the other rationality that can sound the thinking of the counter-reductive rationality in the global world order.

Only in allowing the counter rationalities to sound against the prevailing reductiveness will it be possible to awaken this reductive mind to an awareness of itself as danger and to the possibilities of aufhebung. From naïve immersion into Being to forgetful reduction, we are headed toward an aufhebung, a rising to greater possibility, which brings to a greater realization of engagement these counter positions of the human species. But this will not happen as long as the voices of the other rationalities remain silent. As long as thinkers allow themselves to the subsumed to the reductive thinking determined by Being's Enframing, no fuller realization of human engagement in the world is possible. A new era of Being's ordaining is dawning. It is an era of recovery and growth. Ours is a time when we can embrace a more profound being in the world that was not possible in the era of Enframing, but was not also possible without being ordained into Enframing.

Philosophy at the end of life-as-we-know-it has the task of challenging our complacency in dwelling in the ordained Enframing for it is coming to a turn. Thinkers positioned between rationalities must invite the human thinker to find her potential for creative engagement. But we must also engage the other rationalities marginalized by the aggressive imposition of modern technology in order to inquire into their possibilities for genuine opening. When we discover other ways of thinking and opening to Being, we can rethink the necessity of our patterns of consumption and reduction that are unsustainable. The rationalities of the other have preserved the wisdom of our first naïveté. It is up to the philosophers of these rationalities to bring this wisdom to meet the dominant mind of reductiveness in order to bring forth the second naïveté of the turning. 


\section{Notes}

1. This research was funded by the Commission on Higher Education (CHED) Philippine Higher Education Research Network (PHERNet).

2. This is the significance of the works of Derrida and Levinas as thinkers. They have revealed to our time the necessity of overcoming traditional ontology and totalizing engagements with the other. Their seminal works show us that what is given can only be engaged as the wholly other that cannot be reduced to them same, that only through the deconstruction of totality can we meet the other as other.

3. These works are particularly revealing regarding the rationalities of the marginalized urban population: F. Landa Jocano, Slum as a Way of Life: A Study of Coping Behavior in an Urban Environment, (Quezon City: New Day, 1976) and Paulo Alcazaren, Luis Ferrer, and Benvenuto Icamina, Siyudad Iskwater: The Evolution of Informality As a Dominant Pattern in Philippine Cities (Quezon City: Anvil, 2010).

\section{Works Cited}

Alave, Kristine L. "Philippines Ranks Third on Climate Change Vulnerability List." Philippine Daily Inquirer. 10 Oct. 2011. Web. 15 Jan. 2013.

Alcazaren, Paulo, Luis Ferrer, and Benvenuto Icamina. Lungsod Iskwater: The Evolution of Informality As a Dominant Pattern in Philippine Cities. Pasig City: Anvil, 2010. Print.

Dodds, Walter K. Humanity's Footprint: Momentum, Impact, and Our Global Environment. New York: Columbia UP, 2008. Print.

Gore, Al. Earth in the Balance: Ecology and the Human Spirit. New York: Rodale Books, 2006. Print.

Heidegger, Martin. "Memorial Address." In Discourse on Thinking. Trans. John M. Anderson and E. Hans Freund. New York: Harper \& Row Publishers, 1966. 43-57. Print.

--. “The Question Concerning Technology." In The Question Concerning Technology and other Essays. Trans. William Lovitt. Ed. J. Glenn Gray and Joan Stambaugh. New York: Harper and Row Publishers, 1982. 3-35. Print.

--.. "The Thing." In Poetry Language Thought. Trans. Albert Hofstadter. Ed. J. Glenn Gray. New York: Harper and Row Publishers, 1971. 163-186. Print.

--.."The Turning." The Question Concerning Technology and Other Essays. Trans. William Lovitt. Ed. J. Glenn Gray and Joan Stambaugh. New York: Harper and Row Publishers, 1982. New York: Harper and Row Publishers, 1982. 36-52. Print. Howden, Daniel. "World Oil Supplies Are Set To Run Out Faster Than Expected, Warn Scientists." The Independent. 14 June 2007. Web. 12 Feb. 2012.

Ileto, Reynaldo C. Pasyon and Revolution: Popular Movements in the Philippines, 18401910. Quezon City: Ateneo de Manila UP, 1997. Print. 
Interlandi, Jeneen. "The New Oil: Should Private Companies Control Our Most Precious Natural Resource?” Newsweek. 8 Oct. 2010. Web. 5 Dec. 2012.

Jocano, F. Landa. Slum as a Way of Life: A Study of Coping Behavior in an Urban Environment. Quezon City: New Day, 1976. Print.

Kant, Immanuel. Prolegomena to any Future Metaphysics: and the Letter to Marcus Herz, February 1772. New York: Hackett, 2002. Print.

Marion, Jean-Luc. "The Event, The Given, The Revealed." In Transcendence in Philosophy and Religion. Tr. Beata Starwaska. Ed. James E. Faulconer. Bloomington: Indiana UP, 2003. 87-105. Print.

Nisbett, Richard E., Kaiping Peng, Incheol Choi, and Ara Norenzayan. "Culture and Systems of Thought: Holistic vs. Analytic Cognition." Psychological Review (2001) 291-310. Print.

Roberts, Paul. The End of Food. Boston: Mariner, 2008. Print.

Rodriguez, Agustin Martin G. "The Turning: Evangelization and Uprising." In Juan de Oliver, Declaracion de la Doctrina Christiana en Idioma Tagalog. Ed. Jose M. Cruz. Quezon City: Pulong, 1995. 283-307. Print.

--. "Revolution and the Restoration of a Moral Cosmos: The Thoughts of Bonifacio, Mabini, and Hermano Pule." In Centennial Commemorative Lectures 1998. Manila: Philippine Centennial Commission, 1998. 81-98. Print.

Sachs, Jeffrey D. Commonwealth: Economics for a Crowded Planet. London: Penguin, 2008. Print.

Tauli-Corpuz, Victoria. "Self-Determination and Sustainable Development." In Reclaiming Balance. Ed. Victoria Tauli-Corpuz and Joji Carino. Baguio City: Tebtebba, 2004. 3-74. Print.

Thakker, Dhairya. "1o Countries Worst Hit by Climate Change." Let's Fight Global Warming: A Blog on the Basics and the Complexities of Global Warming and Climate Change. 16 Dec. 2009. Web. 15 Jan. 2013.

Wilson, E.O., et al. "Insights: Human Activities Cause of Current Extinction Crisis." Environment News Service. 19 May 2005. Web. 15 Nov. 2010. 